\title{
Gender and obesity interaction in quality of life in adults assisted by family doctor program in Niterói, Brazil
}

\author{
Interação entre gênero e obesidade na qualidade de vida de adultos \\ assistidos pelo programa médico de família de Niterói, Brasil
}

Karla Dala Paula Torres ${ }^{1}$

Maria Luiza Garcia Rosa ${ }^{1}$

Samuel Datum Moscavitch ${ }^{1}$

${ }^{1}$ Departamento de Epidemiologia e Bioestatística, Universidade Federal Fluminense (UFF). R. Marques do Paraná $303 / 3 \%$ prédio anexo, Centro. 24030-210 Niterói RJ Brasil.

karladptorres@gmail.com
Abstract Obesity impacts the quality of life (HRQL). Studies about the effects of a possible interaction between gender and body mass are rare. The objective of the present paper is to estimate the biological interaction between gender and obesity on HRQL. This was a cross-sectional study based on data from CAMELIA study with population assisted by the Family Doctor Program of Niteroi visited between June 2006 and December 2007. $H R Q L$ was assessed by the SF-36. The exposure categories were: obese women, non-obese women, obese men and non-obese men, the reference category. Obese women showed higher percentages of low overall, physical and mental quality of life with the largest associations in the physical component. The excess risk due to interaction was statistically significant in physical dimension: RERI $=1.97$ (0.40-3.52) and RERIa $=1,97(0.40-$ 1.7). Among the Brazilian population aged 20-64 years, obesity was independently associated with low HRQL. This association differed by gender, being significant for women. The possibility of the combined effect takes greater importance in the context of increasing incidence of obesity globally. Healthcare professionals in primary care settings should pay attention to gender differences in the impact of obesity on HRQL.

Key words Quality of life, Obesity, Gender, Biological interaction
Resumo A obesidade causa impacto na qualidade de vida relacionada à saúde (QVRS). Estudos sobre os efeitos de uma possivivel interação entre sexo e obesidade são escassos. O objetivo do presente trabalho é estimar a interação biológica entre gênero e obesidade na QVRS. Trata-se de um estudo transversal com base em dados do estudo CAMELIA da população atendida pelo Programa Médico de Família de Niterói que ocorreu entre junho de 2006 e dezembro de 2007. A QVRS foi avaliada pelo SF-36. As variáveis de exposição foram: mulheres obesas, mulheres não obesas, homens obesos e homens não obesos, a categoria de referência. As mulheres obesas apresentaram maiores percentuais de baixa qualidade de vida global, física e mental com as maiores associações no componente físico. $O$ excesso de risco devido à interação foi estatisticamente significativo na dimensão física: $R E R I=1,97(0,40-3,52)$ e RERIa $=1,97(0,40-1,7)$. A obesidade na população brasileira com idade entre 20-64 anos foi associada com baixa QVRS. Esta associação difere por sexo, sendo significativa para as mulheres. A possibilidade de um efeito combinado assume maior importância no contexto da crescente incidência de obesidade no mundo. Os profissionais de saúde de atenção primária devem considerar as diferenças de gênero no impacto da obesidade sobre a QVRS. Palavras-chave Qualidade de vida, Obesidade, Gênero, Interação biológica 


\section{Introduction}

In the last decades, the impact on quality of life (QoL) has gained increasing interest as an outcome measure of health status defined as the individual's perception regarding their position in life according to the cultural context and value systems which they live in, agreeing to their goals, expectations, standards and concerns ${ }^{1}$. The concept Health-related quality-of-life (HRQL) adds the issue of disease and health interventions ${ }^{2}$.

It is well established that obesity, which nowadays is considered a pandemic ${ }^{3}$, has a negative impact on HRQL, especially on physical component and women ${ }^{4-8}$. However, studies about the effects of a possible interaction between gender and body mass have been little studied ${ }^{9}$. As gender differences differs by population groups with diverse sociocultural contexts, it is important to study the interaction between gender and body mass in Brazilian population. The biological interaction refers to an action dependency between two or more factors acting in the same cause, enough to produce an outcome, in other words, a factor may potentiate the action of another ${ }^{10,11}$. The aim of this study is to test the hypothesis of biological interaction between gender and body mass on HRQL.

\section{Methods}

This cross-sectional study is a part of the CAMELIA STUDY (Cardio Metabolic-Renal family) which recruited 1098 subjects were from a public primary care program, the Family Doctor Program in Niteroi, Rio de Janeiro, Brazil ${ }^{12}$. Thirteen FDP units were selected by convenience, covering all administrative areas of the city. Families were enrolled following an initial selection of index cases. To be accepted as an index case, subjects were required to be 67 married to a partner who agreed to participate in the study and have at least one descendant between 12 and 30 who would also enroll.

The sample size of the CAMELIA STUDY was based on two studies who found significant associations (family pair correlations above 0.20 ) using 134 and 143 families, respectively ${ }^{13,14}$. The CAMELIA STUDY sought to include a minimum of 143 families (both spouses and at least one child), including 265 families.

The protocol was approved by the Ethics Committee of the Medical School of Universidade Federal Fluminense. Informed written con- sent was obtained from all participants. The participants answered a questionnaire and provided blood and urine samples. The present study included all adults aged 20-64 years, with no history of severe comorbidities such as myocardial infarction, heart failure, cancer and stroke. The individuals who did not answered adequately the SF-36 and those who did not undergo anthropometric measurements were excluded (loss), remaining 605 participants.

The HRQL was evaluated by the SF-36, a general, self-applicable and validated in Brazil questionnaire $^{15}$. The outcomes variables were defined as the scores of the SF-36. The physical component summary (PCS) was the sum of the following the domains: physical functioning, role-physical, bodily pain and general health; for the mental component summary (MCS) we used the sum of: role-emotional, mental health, social functioning, and vitality, and the sum of both PCS and MCS we called the general score.

The Normal distribution was not seen in none of the eight domains. As the median of six dimensions, achieved the maximum score and the two remaining reached $85 \%$, we set the cutoff at $25 \%$ of the maximum as low scoring on HRQL. To analyze the additive interaction, dummy variables were constructed by exposures of interest: non-obese women $(+-)$, obese men ($+)$ and obese women $(++)$, taking as reference the group men non obese (- -). Adjusted and unadjusted odds ratios were estimated by logistic models of generalized estimating equations (GEE). For modeling, we included potentially confounding variables that were associated with HRQL in the bivariate analysis $(\mathrm{p}<0.2)$.

Deviation from additivity were noticed by excess risk due to interaction (RERI), the attributable proportion due to interaction (AP), and synergy index (S) and their confidence intervals at 95\% by pre-programmed Excel spreadsheets ${ }^{16,17}$. Statistical significance was set at $<0.05$. All analyses were performed using SPSS version 17.0 (SPSS Inc., Chicago, USA).

\section{Results}

We surveyed 605 subjects, 55\% women, 72\% under 50 years and 22,5\% were classified as obese. Associations of low HRQL with gender (women), age (older), physical activity (low), depression, hypertension and HDL (low) were statistically significant (Table 1). The overall prevalence of poor HRQL ranged from $13 \%$ among obese men 
Table 1. Distribution of demographic, socioeconomic, behavioral and comorbidities variables according the score of SF-36, lesser and greater than or equal to the percentile 25, total SF-36, physical and mental components. Population sample assisted by PMF of Niterói, Rio de Janeiro, Brazil 2006 to 2007 ( $\mathrm{n}=605)$.

\begin{tabular}{|c|c|c|c|}
\hline Variables & $\begin{array}{c}\text { SF36 < 25\% } \\
\text { N }(\%)\end{array}$ & $\begin{array}{c}\text { SF36 } \geq 25 \% \\
\text { N }(\%)\end{array}$ & $\begin{array}{c}\text { OR } \\
\text { (IC95\%) }\end{array}$ \\
\hline \multicolumn{4}{|l|}{ Gender } \\
\hline Female & $151(45,3)$ & $182(54,7)$ & \\
\hline Male & $79(29,0)$ & $193(71,0)$ & $2,0(1,4-2,8)$ \\
\hline \multicolumn{4}{|l|}{ Age Group } \\
\hline$\geq 50$ years & $54(32,5)$ & $112(67,5)$ & \\
\hline$<50$ years & $97(22,1)$ & $342(77,9)$ & $1,7(1,1-2,5)$ \\
\hline \multicolumn{4}{|l|}{ Skin Color } \\
\hline Black & $57(37,7)$ & $94(62,3)$ & \\
\hline Brown or Caucasian & $172(38,5)$ & $275(61,5)$ & $1,0(0,7-1,4)$ \\
\hline \multicolumn{4}{|l|}{ Scholarity } \\
\hline$\leq 4$ th grade/ 4 years of study & $92(42,0)$ & $127(58,0)$ & \\
\hline$>4$ th grade/4 years of study & $138(35,8)$ & $247(64,2)$ & $1,3(0,9-1,8)$ \\
\hline \multicolumn{4}{|l|}{ Familiar incomes per capita } \\
\hline$\leq \mathrm{R} \$ 200,00$ & $101(40,4)$ & $149(59,6)$ & \\
\hline$>\mathrm{R} \$ 200,00$ & $126(36,2)$ & $222(63,8)$ & $1,2(0,8-1,7)$ \\
\hline \multicolumn{4}{|l|}{ Smoke } \\
\hline Present or past smoker & $114(42,7)$ & $153(57,3)$ & \\
\hline Never smoked & $114(34,0)$ & $221(66,0)$ & $1,4(1,0-2,0)$ \\
\hline \multicolumn{4}{|l|}{ Physical activities } \\
\hline$\leq 150$ minutes/week & $169(41,7)$ & $236(58,3)$ & \\
\hline$>150$ minutes/week & $61(30,5)$ & $139(69,5)$ & $1,6(1,1-2,3)$ \\
\hline \multicolumn{4}{|l|}{ Obesity $^{\mathrm{a}}$} \\
\hline $\mathrm{BMI} \geq 30 \mathrm{~kg} / \mathrm{m}^{2}$ & $62(456)$ & $74(54,4)$ & \\
\hline $\mathrm{BMI}<30 \mathrm{~kg} / \mathrm{m}^{2}$ & $168(35,8)$ & $301(64,2)$ & $1,5(1,0-2,2)$ \\
\hline \multicolumn{4}{|l|}{ Waist Circumference } \\
\hline Women $\geq 80 \mathrm{~cm}$ and $\mathrm{men} \geq 94 \mathrm{~cm}$ & $80(29,2)$ & $194(70,8)$ & \\
\hline Women $<80 \mathrm{~cm}$ and men $<94 \mathrm{~cm}$ & $70(21,2)$ & $260(78,8)$ & $1,5(1,0-2,2)$ \\
\hline \multicolumn{4}{|l|}{ Depression $^{\mathrm{b}}$} \\
\hline Yes & $43(89,6)$ & $5(10,4)$ & \\
\hline No & $175(33,1)$ & $353(66,9)$ & $17,3(6,7-45)$ \\
\hline \multicolumn{4}{|l|}{ Hypertension $^{\mathrm{c}}$} \\
\hline Yes & $108(44,3)$ & $136(55,7)$ & \\
\hline No & $122(34,0)$ & $237(66,0)$ & $1,5(1,1-2,1)$ \\
\hline \multicolumn{4}{|l|}{ Diabetes $^{\mathrm{d}}$} \\
\hline Yes & $37(40,7)$ & $54(59,3)$ & \\
\hline No & $165(38,0)$ & $269(62,0)$ & $1,1(0,7-1,8)$ \\
\hline \multicolumn{4}{|l|}{ Unsettled HDL_C ${ }^{\mathrm{e}}$} \\
\hline Yes & $89(47,3)$ & $99(52,7)$ & \\
\hline No & $106(32,9)$ & $216(67,1)$ & $1,8(1,3-2,6)$ \\
\hline \multicolumn{4}{|l|}{ Unsettled Triglycerides $^{\mathrm{f}}$} \\
\hline Yes & $44(41,1)$ & $63(58,9)$ & \\
\hline No & $239(59,0)$ & $166(41,0)$ & $1,2(0,8-1,8)$ \\
\hline
\end{tabular}

and $40 \%$ among obese women. The crude and adjusted OR of low overall HRQL were higher in females, which did not happen with exposure to obesity alone (Table 2). 


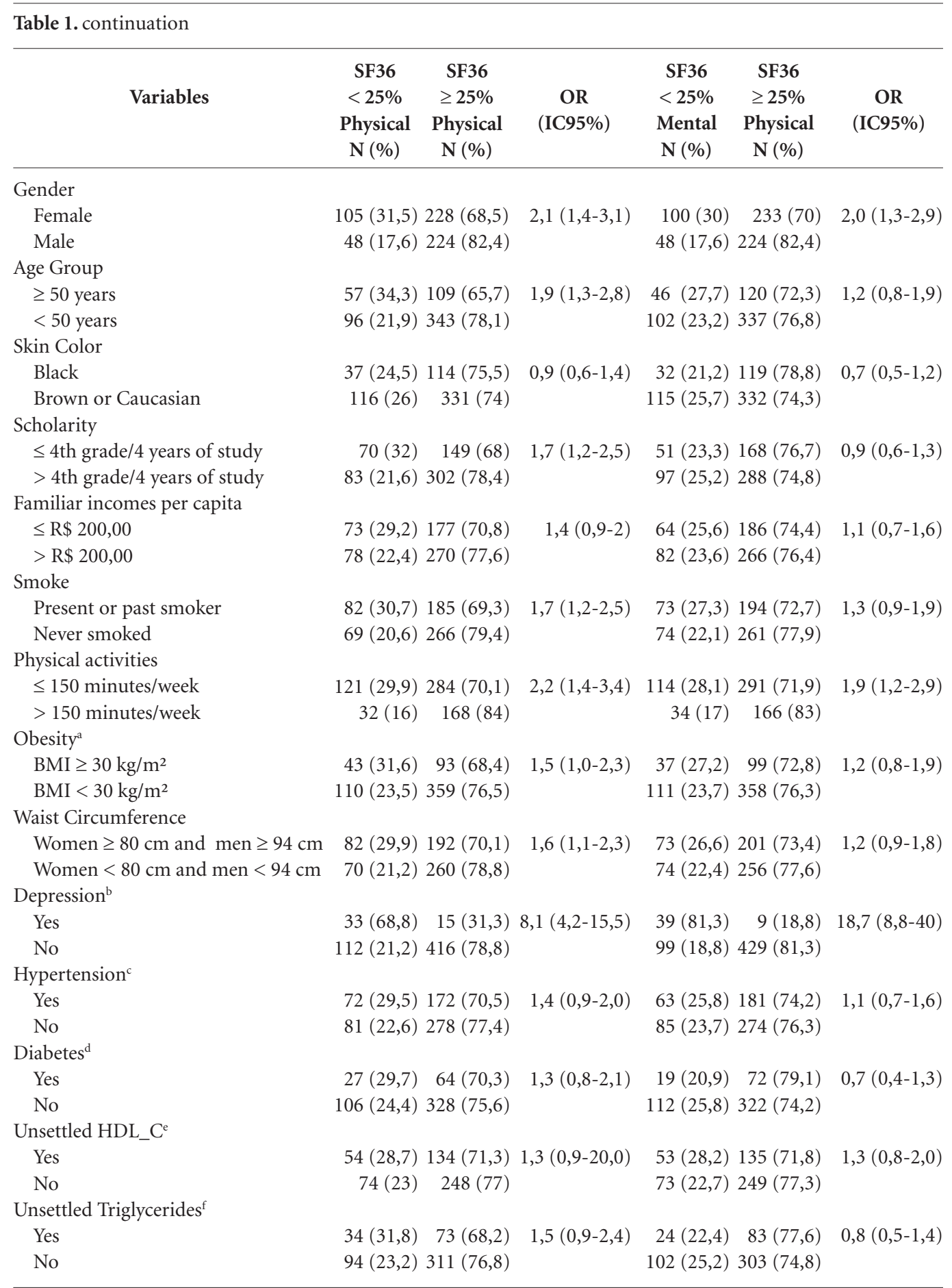

a BMI - body mass index, measured by the ratio weight in kilograms/height in meters squared. ${ }^{\mathrm{b}}$ Measured by Beck Depression Inventory 19 points as cutoff depression tracking. ${ }^{c}$ Previous diagnosis of hypertension or AP $\geq 140 \times 90 \mathrm{mmHg}$. ${ }^{\mathrm{d}}$ Previous diagnosis of Diabetes or fasting plasma glucose (FPG) $\geq 126 \mathrm{mg} / \mathrm{dl} .{ }^{\mathrm{e}} \mathrm{HDL} \leq 50 \mathrm{mg} / \mathrm{dL}$ women and $\leq 40 \mathrm{mg} / \mathrm{dL}$ men. ${ }^{\mathrm{f}}$ Triglycerides $\geq 150 \mathrm{mg} / \mathrm{dL}$.

tion additive (RERI) was 1.54 on the scale as a whole, the PCS of 1.97 and 0.61 in MCS, and the difference was statistically significant only in PCS. After adjustment, the additional risks have decreased, but the difference in physical part remained statistically significant. The proportion of lower HRQL general, physical and mental, assigned to additive interaction was $48 \%, 63 \%$ 
and $26 \%$ respectively, and the difference between general HRQL and PCS statistically significant.

In multivariate analysis, the percentages of overall scale and MCS decreased, but increased the PCS, in which adjusted difference remained statistically significant. Comparing to the Synergy Index, which represents the excess risk of exposure to risk factors when interaction is present, in relation to risk of exposure when interaction is absent, the rates of total synergy, physical and mental, not reached statistical significance (Table 3 ).

\section{Discussion}

The present study confirmed the assumption of biological interaction between obesity and sex to low HRQL. The chance of obese women to present lower HRQL, compared to non-obese women and obese men, exceeded the sum of the odds ratios of the other groups. Obese women had the higher OR of low HRQL in the scale as a whole, in the PCS and MCS, followed by thin women and thin men. Obese men had better scores. The

Table 2. Distribution and prevalence of low HRQL (total, physical and mental) among the groups of effects isolated or combined between women and obesity, Odds Ratio (OR) and adjusted (ORa), confidence interval (CI 95\%). Population sample assisted by PMF of Niterói, Rio de Janeiro, Brazil 2006 to 2007 ( $\mathrm{n}=605)$.

\begin{tabular}{|c|c|c|c|c|c|c|c|}
\hline \multirow{2}{*}{ Obesity } & \multirow{2}{*}{ Woman } & \multicolumn{6}{|c|}{ Low Total HRQL } \\
\hline & & $\mathbf{N}$ & $(\%)$ & OR & CI 95\% & $\mathrm{ORa}^{*}$ & CI 95\% \\
\hline No & No & 39 & 17,2 & 1 & Reference & 1 & Reference \\
\hline Yes & No & 6 & 13 & 0,72 & $0,28-1,81$ & 0,69 & $0,16-2,96$ \\
\hline No & Yes & 70 & 28,8 & 1,93 & $1,28-2,89$ & 1,71 & $0,89-3,27$ \\
\hline Yes & Yes & 36 & 40 & 3,18 & $1,86-5,42$ & 2,35 & $1,11-4,96$ \\
\hline \multirow{2}{*}{ Obesity } & \multirow{2}{*}{ Woman } & \multicolumn{6}{|c|}{ Low Physical HRQL } \\
\hline & & $\mathrm{N}$ & $(\%)$ & OR & CI 95\% & $\mathrm{ORa}^{*}$ & CI 95\% \\
\hline No & No & 43 & 19 & 1 & Reference & 1 & Reference \\
\hline Yes & No & 5 & 10,9 & 0,52 & $0,19-1,41$ & 0,26 & $0,05-1,36$ \\
\hline No & Yes & 67 & 27,5 & 1,62 & $1,07-2,43$ & 1,17 & $0,68-2,03$ \\
\hline Yes & Yes & 38 & 42,2 & 3,11 & $1,80-5,32$ & 2,13 & $1,08-4,21$ \\
\hline \multirow{2}{*}{ Obesity } & \multirow{2}{*}{ Woman } & \multicolumn{6}{|c|}{ Low Mental HRQL } \\
\hline & & $\mathbf{N}$ & $(\%)$ & OR & CI 95\% & $\mathrm{ORa}^{*}$ & CI 95\% \\
\hline No & No & 41 & 18,1 & 1 & Reference & 1 & Reference \\
\hline Yes & No & 7 & 15,2 & 0,83 & $0,34-2,01$ & 1,10 & $0,23-5,35$ \\
\hline No & Yes & 70 & 28,8 & 1,87 & $1,24-2,82$ & 1,22 & $0,62-2,39$ \\
\hline Yes & Yes & 30 & 33,3 & 2,31 & $1,37-3,91$ & 1,38 & $0,62-3,04$ \\
\hline
\end{tabular}

*Adjusted by age, smoking, physical activity, diabetes, hypertension, HDL, triglycerides and depression.

Table 3. Relative excess risk (RERI), assigned proportion due to the interaction (AP) and synergy index (S) of interaction between women and obesity to low HRQL (total, physical and mental). Population sample assisted by PMF of Niterói, Rio de Janeiro, Brazil 2006 to $2007(\mathrm{n}=605)$.

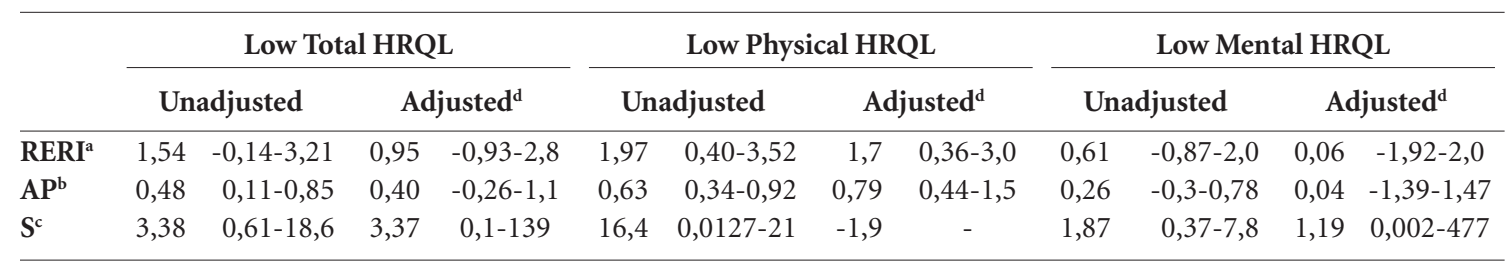

${ }^{\mathrm{a}} \mathrm{RERI}=1+\mathrm{OR} 11-\mathrm{OR} 10-\mathrm{OR} 01 .{ }^{\mathrm{b}} \mathrm{AP}=\mathrm{RERI} / \mathrm{OR} 11 .{ }^{\mathrm{c}} \mathrm{S}=\mathrm{OR} 11-1 / \mathrm{OR} 10+\mathrm{OR} 01-2 .{ }^{\mathrm{d}}$ Adjusted by age, smoking, physical activity, diabetes, hypertension, HDL, triglycerides and depression. 
worst score of obese women compared to men has been described in numerous studies. Choo et al. found similar results for Korean population'.

Women report worst health and psychological problems in most countries, use more health services and experience greater burden of chronic diseases ${ }^{18,19}$. However, in general, men develop more serious diseases that contribute to the highest mortality in this group ${ }^{19,20}$.

In our study, the OR of low scores on the SF36, indicating low HRQL of obese women was higher in the physical component. The index of bodily pain seems to be larger and more varied among women, responding differently to drugs due to neural and hormonal differences and development between the genders ${ }^{19,21}$. Perhaps, these differences may partly explain the greater reflection on the HRQL in the physical component of the obese woman compared to obese man.

Obese women also had worst scores on the mental component, in line with other studies ${ }^{22,23}$. Psychosocial and cultural pressures imposed mainly to women, make them suffer more with the subjective effects of being overweight having greater interference in self-esteem ${ }^{24}$.

The finding that the obese man has a lower OR of lower HRQL than non-obese men is discordant with the literature $e^{4,7,8}$. However, other studies indicate that the association between obese men and low HRQL is significant only in the physical domains, in other words, men are affected mainly by the physical consequences of the disease $\mathrm{e}^{23,25}$.

The analysis and interpretation of the results of this study are based on the concept of biological interaction, a result of synergism between two factors, and responsible for generating more cases of a disease or condition that would be expected from the sum of their independent actions ${ }^{10,11}$. Therefore, the hypothesis is based on the co-participation of two factors responsible for the development of the disease in a portion of the population that does not get sick if exposed to only one of him ${ }^{10,11}$. In our case, there was an excess of cases of low HRQL in obese women.
The mechanism underlying the hypothesis of interaction between female sex and obesity to the impact on HRQL may include genetic or biological matter such as body composition - that relates to the variable performance like strength and endurance - and psychological and social variables, how women, unlike men, perceive their physical appearance and are more susceptible to mental suffering.

Some limitations of the study should be highlighted, the sample size may have affected the power of the study, hypothesis tests for additivity has low power when applied to traditional sample sizes, which is reflected in the poor accuracy of the corresponding estimates, as RERI ${ }^{10}$. Even with low precision, the outcome studies of interaction, that points to possible combined effects, biologically plausible, and susceptible to intervention processes for preventing new cases, without prejudice to the population, should be valued.

Although the results were favorable to the hypothesis of biological interaction, the cross-sectional design is limited to causal inference, thus should be interpreted with caution. We also emphasize that we seek to minimize the effect of confounding factors by controlling the variables associated with the exposures and outcomes involved in the analysis. The differences seen in this study cannot be generalized to the population overall, as they are based on a subjective measure that can vary between populations of different cultural, social realities and historical periods.

The results of this study support the hypothesis of biological interaction between sex and obesity on HRQL. This study contributes to public health with the warning that an excess of cases of low HRQL is related to the combination: woman and obesity. The possibility of the combined effect takes greater importance in the current context, in which the incidence of obesity is increasing globally. Healthcare professionals in primary care settings should pay attention to gender differences in the impact of obesity on HRQL. 


\section{Collaborations}

KDP Torres worded in study conception and design, acquisition of data, analysis and interpretation of data, drafting of manuscript and critical revision. MLG Rosa worded in study conception and design, analysis and interpretation of data, drafting of manuscript and critical revision. SD Moscavitch worked in analysis and interpretation of data;vdrafting of manuscript and critical revision.

\section{References}

1. The World Health Organization quality of life assessment (WHOQOL): position paper from the World Health Organization. Soc Sci Med 1995; 41(10):14031409.

2. Centers for Disease Control and Prevention, National Center for Chronic Disease Prevention and Health Promotion. Measuring Healthy Days. Population Assessment of Health-Related Quality of Life. Division of Adult and Community Health [Internet]. Atlanta-Geogia: CDC; 2000. [acessado 2013 nov 2]. Disponível em: http://www.cdc.gov/hrqol/pdfs/mhd.pdf

3. Organização Mundial da Saúde (OMS). Obesidade: prevenindo e controlando a epidemia global. São Paulo: Roca; 2004.

4. Larsson U, Karlsson J, Sullivan M. Impact of overweight and obesity on health-related quality of life--a Swedish population study. Int J Obes Relat Metab Disord 2002; 26(3):417-424.

5. Dinç G, Eser E, Saatli GL, Cihan UA, Oral A, Baydur H, Ozcan C. The relationship between obesity and health related quality of life of women in a Turkish city with a high prevalence of obesity. Asia Pac J Clin Nutr 2006; 15(4):508-515.

6. Mond JM, Baune BT. Overweight, medical comorbidity and health-related quality of life in a community sample of women and men. Obesity (Silver Spring) 2009; 17(8):1627-1634.

7. Soltoft F, Hammer M, Kragh N. The association of body mass index and health-related quality of life in the general population: data from the 2003 Health Survey of England. Qual Life Res 2009; 18(10):1293-1299.

8. Wee HL, Wu Y, Thumboo J, Lee J, Tai ES. Association of body mass index with Short-Form 36 physical and mental component summary scores in a multiethnic Asian population. Int J Obes (Lond) 2010; 34(6):10341043.

9. Choo J, Jeon S, Lee J. Gender differences in health-related quality of life associated with abdominal obesity in a Korean population. BMJ Open 2014; 4:e003954.

10. Rothman KJ, Greenland S. Modern Epidemiology. $2^{\text {nd }}$ edition. Philadelphia: Lippincott Williams and Wilkins; 1998.

11. Kalilani L, Atashili J. Measuring additive interaction using odds ratios. Epidemiol Perspect Innov 2006; 3:5.

12. de Miranda VA, Cruz Filho RA, de Oliveira TS, Moscavitch SD, Kang HC, Miranda Chagas SV, Costa DM, Vianna Araújo D, Garcia Rosa ML. Racial differences in HbAlc: a cross-sectional analysis of a Brazilian public primary care population. Prim Care Diabetes 2013; 7(2):135-141.

13. Park HS, Park JY, Cho SI. Familial aggregation of the metabolic syndrome in Korean families with adolescents. Atherosclerosis 2006; 186(1):215-221.

14. Martínez Vizcaíno V, Salcedo Aguilar F, Franquelo Gutiérrez R, Jarabo Crespo Y, García Navalón P, Domínguez Rojas V. Familial aggregation of cardiovascular disease risk factors: the Cuenca Study. Prev Med 1999; 28(2):131-137.

15. Ciconelli RM, Ferraz MB, Santos W, Meinão I, Quaresma MR. Tradução para a língua portuguesa e validação do questionário genérico de avaliação de qualidade de vida SF-36. Rev Bras Reumatol 1999; 39(3):143-150. 
16. Knol MJ, VanderWeele TJ, Groenwold RH, Klungel $\mathrm{OH}$, Rovers MM, Grobbee DE. Estimating measures of interaction on an additive scale for preventive exposures. Eur J Epidemiol 2011; 26(6):433-438.

17. Knol MJ, VanderWeele TJ. Recommendations for presenting analyses of effect modification and interaction. Int J Epidemiol 2012; 41(2):514-520.

18. Verbrugge LM, Wingard DL. Sex differentials in health and mortality. Women \& Health 1987; 12(2):103-145.

19. Macintyre S, Hunt K, Sweeting H. Gender differences in health: are things really as simple as they seem? Soc Sci Med 1996; 42(4):617-624.

20. Bird CE, Rieker PP. Gender matters: an integrated model for understanding men's and women's health. Soc Sci Med 1999; 48(6):745-755.

21. Berkley KJ, Zalcman SS, Simon VR. Sex and gender differences in pain and inflammation: a rapidly maturing field. Am J Physiol Regul Integr Comp Physiol 2006; 291(2):241-244.

22. Vasiljevic N, Ralevic S, Marinkovic J, Kocev N, Maksimovic M, Milosevic GS, Tomic J. The assessment of health-related quality of life in relation to the body mass index value in the urban population of Belgrade. Health Qual Life Outcomes 2008; 6:106.

23. Mannucci E, Petroni ML, Villanova N, Rotella CM, Apolone G, Marchesini G; QUOVADIS Study Group. Clinical and psychological correlates of health-related quality of life in obese patients. Health Qual Life Outcomes. 2010; 8:90.

24. Maine MD. Eating disorders and body image distress in women at midlife. Medscape Today 2005. [acessado 2013 nov 8]. Disponível em: http://www.medscape. org/viewarticle/508299

25. Ford ES, Moriarty DG, Zack MM, Mokdad AH, Chapman DP. Self-reported body mass index and health-related quality of life: findings from the Behavioral Risk Factor Surveillance System. Obes Res 2001; 9(1):21-31.

Artigo apresentado em 20/06/2015

Aprovado em 16/11/2015

Versão final apresentada em 18/11/2015 